\title{
Effect of bupivacaine and adjuvant drugs for regional anesthesia on nerve tissue oximetry and nerve blood flow
}

This article was published in the following Dove Press journal: Journal of Pain Research

\author{
Thomas Wiesmann' \\ Stefan Müller ${ }^{1,2}$ \\ Hans-Helge Müller ${ }^{3}$ \\ Hinnerk Wulf' \\ Thorsten Steinfeldt ${ }^{1,4}$ \\ 'Department of Anesthesiology and \\ Intensive Care Medicine, Faculty \\ of Medicine, University Hospital \\ Marburg, Philipps University, Marburg, \\ ${ }^{2}$ Department of Anesthesiology and \\ Intensive Care Medicine, University \\ Hospital Giessen, Justus-Liebig- \\ University, Giessen, Institute of \\ Medical Biometry and Epidemiology, \\ Philipps University, Marburg, \\ ${ }^{4}$ Department of Anesthesiology \\ and Intensive Care Medicine, \\ Diakoniekrankenhaus Schwäbisch Hall, \\ Schwäbisch Hall, Germany
}

Background: Nerve blood flow has a critical role in acute and chronic pathologies in peripheral nerves. Influences of local anesthetics and adjuvants on tissue perfusion and oxygenation are deemed as relevant factors for nerve damage after peripheral regional anesthesia. The link between low tissue perfusion due to local anesthetics and resulting tissue oxygenation is unclear. Methods: Combined tissue spectrophotometry and laser-Doppler flowmetry were used to assess nerve blood flow in 40 surgically exposed median nerves in pigs, as well as nerve tissue oximetry for $60 \mathrm{~min}$. After baseline measurements, test solutions saline (S), bupivacaine (Bupi), bupivacaine with epinephrine (BupiEpi), and bupivacaine with clonidine (BupiCloni) were applied topically. Results: Bupivacaine resulted in significant decrease in nerve blood flow, as well as tissue oximetry values, compared with saline control. Addition of epinephrine resulted in a rapid, but nonsignificant, reduction of nerve blood flow and extensive lowering of tissue oximetry levels. The use of clonidine resulted in a reduction of nerve blood flow, comparable to bupivacaine alone (relative blood flow at T60 min compared with baseline, S: 0.86 (0.67-1.18), median (25th-75th percentile); Bupi: 0.33 (0.25-0.60); BupiCloni: 0.43 (0.38-0.63); and BupiEpi: 0.41(0.30-0.54). The use of adjuvants did not result in any relevant impairment of tissue oximetry values (saturation values in percent at T60, S: 91.5 [84-95]; Bupi: 76 [61-86]; BupiCloni: 84.5 [76-91]; and BupiEpi: 91 [56-92]).

Conclusion: The application of bupivacaine results in lower nerve blood flow, but does not induce relevant ischemia. Despite significant reductions in nerve blood flow, the addition of clonidine or epinephrine to bupivacaine had no significant impact on nerve tissue oximetry compared with bupivacaine alone. Nerve ischemia due to local anesthetics is not enhanced by the adjuvants clonidine or epinephrine.

Keywords: peripheral regional anesthesia, complications, nerve blood flow, local anesthetics, adjuvants

\section{Introduction}

The blood supply to peripheral nerves is delivered by two integrated, but functionally independent, vascular systems. ${ }^{1,2}$ Extrinsic and intrinsic vessels form anastomoses at the level of the epineurium. Alterations in blood flow are important for peripheral nerve pathology in acute and chronic disease. ${ }^{3-6}$ Local anesthetics and epinephrine, used as an adjunct, are known to have a negative impact on nerve blood flow. ${ }^{4,8}$ The underlying molecular mechanisms of local anesthetic-induced reductions of nerve blood flow are still uncertain and speculative. ${ }^{9}$ Additionally, it is unclear whether these blood flow reductions, caused by local anesthetics, result in local hypoxic tissue conditions and act as a key factor for peripheral nerve injury. ${ }^{5,6}$ The goal of this study is to determine the effect of bupivacaine alone and in combination with the adjuncts epinephrine or
Correspondence: Thomas Wiesmann Department of Anesthesiology and Intensive Care Medicine, Faculty of Medicine, University Hospital Marburg, Philipps University, Baldingerstrasse 10 Marburg 35032, Germany

Tel +4964215869362

Fax +49 642I 586 597I

Email wiesmann@med.uni-marburg.de 
clonidine on nerve blood flow and tissue oximetry in a large animal model, simulating human conditions. Thus, data for epinephrine and clonidine, with regard to neural ischemia as a potential risk factor for nerve damage, could be investigated in our study.

\section{Methods}

\section{General anesthesia and nerve preparation}

Experiments were approved by the local authorities (Study No. 93/11; Regional Board of Animal Welfare, Giessen, Germany); study results are presented according to ARRIVE guidelines. ${ }^{10}$ Experiments were performed in accordance with the current German laws of animal protection. Standardized general anesthesia and euthanasia, following the experiments, were conducted as described previously. ${ }^{11,12}$ In brief, following a premedication using diazepam and ketamine, general anesthesia was induced using propofol (2-3 $\mathrm{mg} \cdot \mathrm{kg}^{-1}$ and sufentanil). After endotracheal intubation, general anesthesia was commenced using propofol $\left(0.2 \mathrm{mg} \cdot \mathrm{kg}^{-1} \cdot \mathrm{min}^{-1}\right)$ and sufentanil $\left(0.5 \mu \mathrm{g} \mathrm{kg}^{-1} \mathrm{~h}^{-1}\right)$. Mechanical ventilation settings were modified to obtain an end tidal $\mathrm{CO}_{2}$ of $35-45 \mathrm{mmHg}$. Inspiratory oxygen fraction was set to $30 \%$ (to simulate clinical conditions, using low-flow oxygen supplementation in spontaneously breathing subjects). Ultrasound-guided invasive blood pressure measurement was conducted via catheter to the left femoral artery. To achieve standardized conditions and minimize motion artifacts for the measurements, pancuronium bromide $\left(0.1 \mathrm{mg} \cdot \mathrm{kg}^{-1}\right)$ was given repeatedly during the study period.
Pharyngeal temperature was recorded and kept constant using warm blankets.

The anesthetized animals were placed supine, and axillary regions were dissected surgically as previously described; ${ }^{11,13}$ median nerves were exposed with preservation of the extrinsic epineural blood vessel supply.

Euthanasia was performed at the end of the experiments under general anesthesia using potassium chloride (4 $\left.\mathrm{mmol} \cdot \mathrm{kg}^{-1}\right)$.

\section{Combined tissue spectrophotometry and laser-Doppler flowmetry}

Measurements of nerve blood flow (flow in arbitrary units $[\mathrm{AU}])$, tissue oxygen saturation $\left(\mathrm{SO}_{2}\right.$ in \%), and tissue hemoglobin level $(\mathrm{rHb}$, in $\mathrm{AU})$ were obtained using laserDoppler flowmetry and tissue spectrophotometry $(\mathrm{O} 2 \mathrm{C}$; Lea Medizintechnik, Giessen, Germany). The system and probe (LF-1; Lea, Medizintechnik) were calibrated according to the manufacturer's recommendation. The $\mathrm{O} 2 \mathrm{C}$ probe was applied to the exposed nerve with a custom-made application device (Figure 1), and fixed with sutures in the surrounding tissue for constant application pressure, to acquire a test volume of 1-2 mm deep inside the nerve, according to the manufacturer's advice. Measurements were started $10 \mathrm{~min}$ before each intervention to achieve optimal measurement stability of the system. One milliliter of the randomly assigned test solution was applied directly to the median nerve next to the probe (resulting in spread under the probe due to capillary effects) immediately after acquiring data at T0.

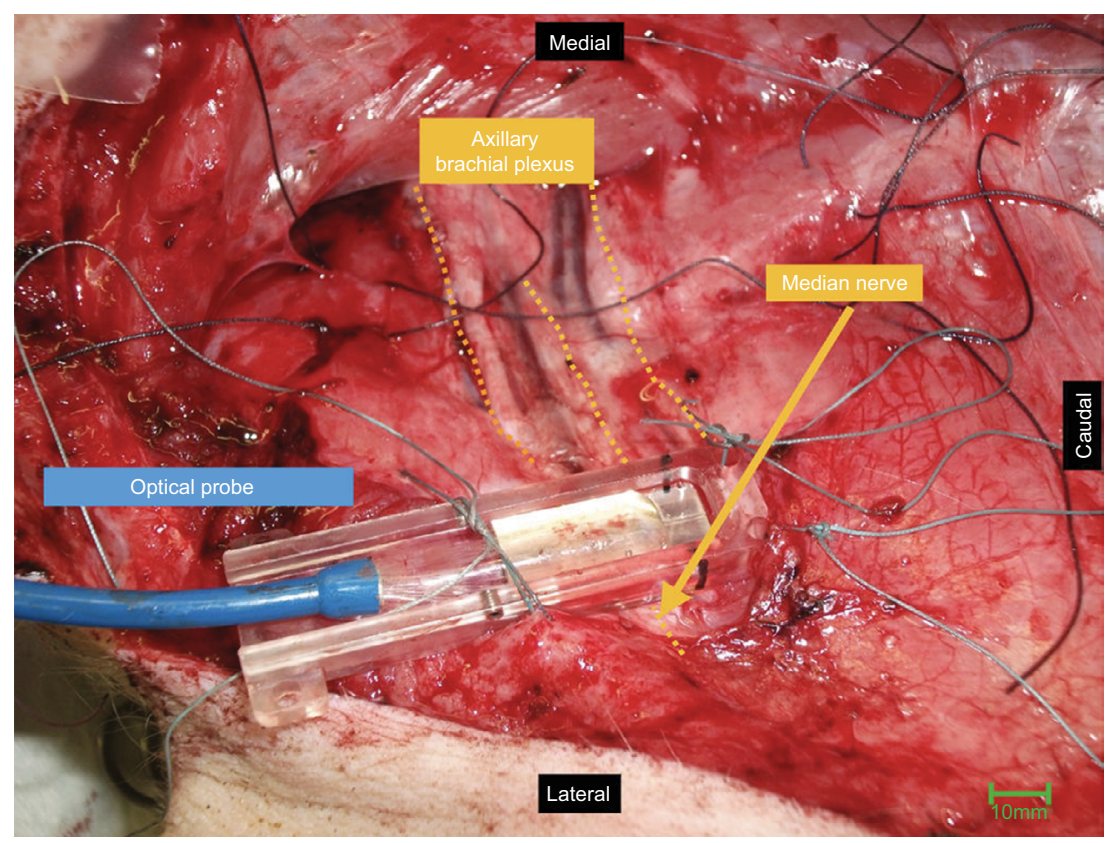

Figure I O2C probe in situ, mounted on median nerve. 
The O2C machine consists of two different units (Figure 2). First, blood flow (flow) is measured by using the technique of laser-Doppler flowmetry, which has been described previously. ${ }^{14-16}$ Second, the tissue spectrophotometry unit calculates tissue hemoglobin content and tissue oximetry. In brief, underlying tissue is illuminated with coherent laser light of 500-630 nm wavelength and $30 \mathrm{~mW}$ power through a fiber-optic cable. Probe geometry allows for the detection of blood flow at $\sim 1-2 \mathrm{~mm}$ depth by analyzing backscattered light. By fitting measured spectra with spectra of known tissue saturation values $\left(\mathrm{SO}_{2}\right)$, the $\mathrm{SO}_{2}$ of the capillary and post-capillary microvasculature is calculated by the $\mathrm{O} 2 \mathrm{C}$ device. The tissue hemoglobin value $(\mathrm{rHb})$ represents the hemoglobin concentration per tissue volume (displayed as arbitrary unit). It is dependent on microvessel density, venous filling and microvessel shunting. This parameter is helpful to rule out venous congestion (raising $\mathrm{rHb}$ value).

Reductions of nerve blood flow are categorized as minimal ( $<20 \%$ reduction of nerve blood flow [NBF] baseline), mild $(20 \%-50 \%$ reduction of NBF), moderate $(50 \%-80 \%$ reduction of NBF) or severe ( $>80 \%$ reduction of NBF) according to structural or electrophysiological signs of tissue damage or electrophysiological conduction impairment as previously described. ${ }^{17-19}$

\section{Study groups}

Randomly, $1 \mathrm{~mL}$ of the following test solutions was applied topically to the nerve: bupivacaine $0.5 \%$ isobaric (Bupi)
(Carbostesin, B. Braun, Melsungen, Germany); bupivacaine 0.5\% with epinephrine 1:100.000 (BupiEpi) (Suprarenin, Sanofi-Aventis, Frankfurt, Germany); bupivacaine $0.5 \%$ (see previous section) with $3.75 \mu \mathrm{g} / \mathrm{mL}$ clonidine (BupiCloni) (Clonidin-ratiopharm, Ratiopharm, Ulm, Germany). In addition, saline was used as a negative control: saline $0.9 \%$ isotonic $(\mathrm{NaCl}, \mathrm{B}$. Braun).

Test solutions were prepared freshly before use for the experiments in a standardized fashion using single-dose vials avoiding preparations containing preservatives like sodium metabisulfite. The concentrations of epinephrine and clonidine resemble the highest concentration of epinephrine used in clinical studies. ${ }^{20}$ Only one nerve per exposed brachial plexus was exposed to only one test solution to avoid potential residual drug effects on the sample.

\section{Outcome parameters}

At the time points T0, T5, T10, T15, T20, T25, T30, T40, $\mathrm{T} 50$, and $\mathrm{T} 60$, the $\mathrm{O} 2 \mathrm{C}$ data of blood flow (flow, in $\mathrm{AU}$ ), tissue oximetry ( $\mathrm{SO}_{2}$, in percent), and hemoglobin $(\mathrm{rHb}$, in $\mathrm{AU}$ ) were recorded using Excel (Excel for Mac; Microsoft Corporation, Redmond, WA, USA). Parameters of systemic hemodynamics (heart rate, mean arterial pressure), as well as oxygen saturation were recorded at $\mathrm{T} 0, \mathrm{~T} 30$, and $\mathrm{T} 60$.

\section{Sample size calculation}

Based on published data for nerve blood flow alterations after the application of local anesthetic, we assumed a relative change of nerve blood flow of 1.0 (no change) for saline

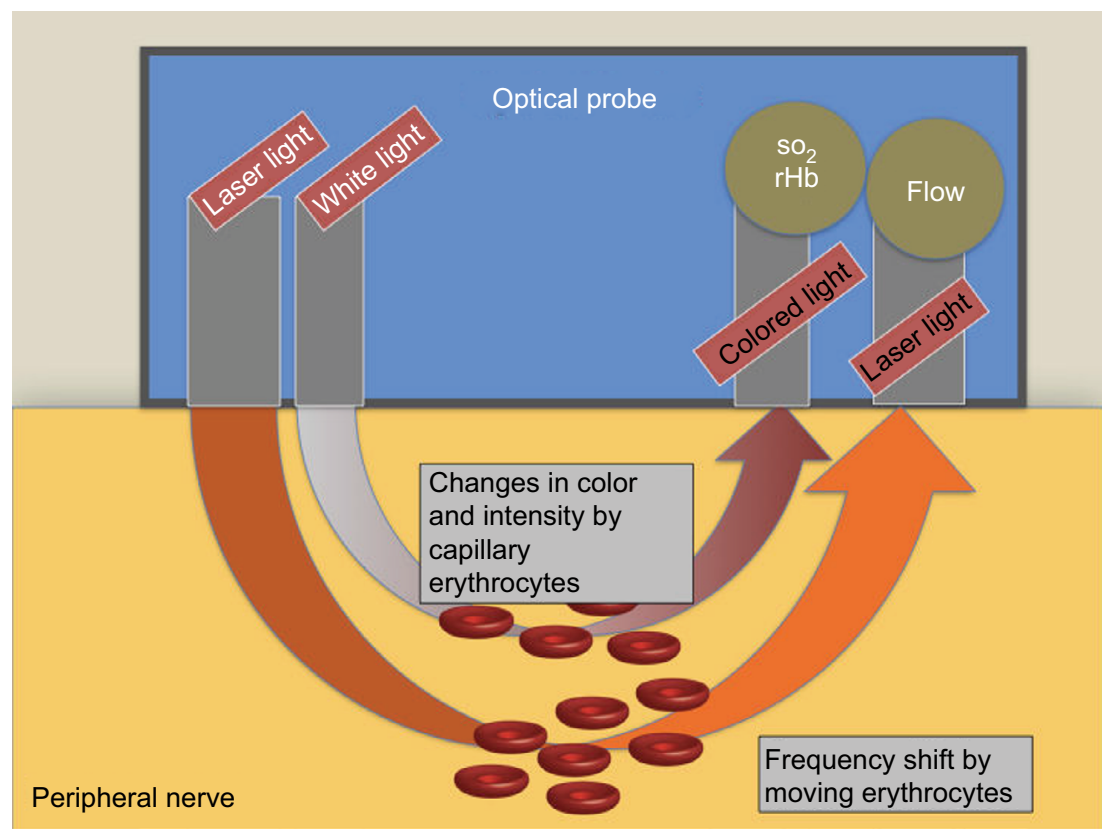

Figure 2 Schematic illustration of $\mathrm{O} 2 \mathrm{C}$ device.

Abbreviations: $\mathrm{SO}_{2}$, tissue oxygen saturation; $\mathrm{rHb}$, tissue hemoglobin. 
(negative control group), and compared with T0 and T60 values. Based on published data of nerve blood flow measurements, we assumed a reduction to 0.6 for bupivacaine (standard group), 0.8 for BupiCloni (intervention group), and 0.4 for BupiEpi (intervention group) at T60, compared with baseline flow at T0. ${ }^{9}$ With an assumed standard deviation of $10 \%$, a power of $80 \%$, and a two-sided testing, a minimum number of seven to eight nerves per group were calculated for semi-parametric testing. Due to multiple testing (two comparisons between bupivacaine and each intervention group), the sample size calculation increased to $n=9$ per group. Considering a dropout rate due to accidental bleeding or technical problems of data acquisition, we planned to perform measurements in 10 nerves per group.

\section{Exclusion criteria}

Exposed nerves were not used for the experiments when epineural blood vessels were damaged during surgical dissection. Obtained measurements for each given nerve were investigated (blinded to the respective group) for signs of technical problems during the test period, or the baseline period, before starting the test period, and were excluded if:

- Continuous data acquisition was not correctly performed over the test period for a respective nerve (mostly due to inadvertent probe dislocation).

- Spectra analysis of the raw data showed incorrect values for hemoglobin extinction (tissue compression due to probe placement).

\section{Statistical analysis}

Data were analyzed using SPSS (SPSS for Windows, release 18.0). Values for $\mathrm{SO}_{2}$ are given as percentage (\%) and values for $\mathrm{rHb}$ are presented in arbitrary units (AU) according to the manufacturer, ${ }^{21}$ and are presented as absolute values at the given time points. Values for blood flow are presented as relative flow compared to baseline flow measurement, according to previous studies..$^{4,9}$

Values of relative flow (AU), $\mathrm{SO}_{2}(\%)$, and $\mathrm{rHb}(\mathrm{AU})$ at T0, T30, and T60 of bupivacaine (standard group) was compared with either BupiEpi or BupiCloni (experimental groups) using Mann-Whitney $U$-test. The saline group served only as a negative control group in comparison with the bupivacaine group. Statistical tests for differences (two-sided) were deemed significant at a level of 0.05 . A closed testing approach was used to compensate for multiple testing: Bonferroni adjustment corrected the level of significance for the two primary comparisons of groups, and the hierarchy of testing according to the primary end points and the time points was relative flow at $\mathrm{T} 60, \mathrm{SO}_{2}$ at $\mathrm{T} 60, \mathrm{rHb}$ at $\mathrm{T} 60$, relative flow at $\mathrm{T} 30, \mathrm{SO}_{2}$ at $\mathrm{T} 30$, and $\mathrm{rHb}$ at $\mathrm{T} 30$. HodgesLehmann (HL) estimators, with 95\% confidence intervals (CI), were calculated for the interpretation of differences between microcirculation parameters $\left(\mathrm{SO}_{2}\right.$ and nerve blood flow) between bupivacaine and each respective group.

Additionally, descriptive post hoc testing was performed comparing $\mathrm{SO}_{2}$ and nerve blood flow parameters at $\mathrm{T} 0$, T30, and T60 between all groups using the Kruskal-Wallis testing (two-sided testing, level of significance 0.05). In case of significance, pairwise comparisons of the saline group versus bupivacaine, BupiEpi, or BupiCloni groups were performed.

Furthermore, to exclude the potential bias of varying vital parameters between groups, vital parameters at T0, T30, and T60 were compared. In this analysis, HL estimators $(95 \% \mathrm{CI})$ for heart rate $(\mathrm{bpm})$, mean blood pressure (MAP, $\mathrm{mmHg}$ ), and $\mathrm{SpO}_{2}\left(\mathrm{SpO}_{2} \%\right)$ were calculated between the bupivacaine group and one of the respective groups. Differences of less than $10 \mathrm{bpm}, 5 \mathrm{mmHg}$ in MAP, or 3\% in $\mathrm{SpO}_{2}$ among the compared groups were assumed to be clinically irrelevant.

\section{Results}

\section{Number of animals and obtained measurements}

Fifty-six peripheral nerves (one nerve per brachial plexus) were exposed in 28 pigs. Six nerves were excluded before randomization due to difficulties in probe mounting, or were used for surgical preparation training. According to the predefined criteria for study termination, three peripheral nerves were excluded from the study due to insufficient surgical preparation of the nerve, with suspected injury to the extrinsic nerve vasculature. Furthermore, seven nerves were excluded before data analysis, due to supposed probe dislocation and non-continuous data acquisition. Thus, 40 nerves were randomly assigned to one of the four experimental groups, and included in the final data analysis $(\mathrm{n}=$ 10 per group).

\section{Vital parameters}

Vital parameter data are given in Table 1. Comparison of HL estimators for mean arterial pressure, heart rate, and systemic pulse oximetry revealed no clinically relevant differences between the groups at T0, T30, and T60 min (Table 1). 
Table I Vital parameters

\begin{tabular}{|c|c|c|c|c|c|c|c|}
\hline Group & Parameter & T0 & HL $(95 \% \mathrm{Cl})$ & T30 & HL $(95 \% \mathrm{Cl})$ & T60 & HL (95\% Cl) \\
\hline Bupi & Heart rate & $97(8 \mathrm{I}-108)$ & $\mathrm{n} / \mathrm{a}$ & 97 (83-99) & $\mathrm{n} / \mathrm{a}$ & $92(84-102)$ & $\mathrm{n} / \mathrm{a}$ \\
\hline \multirow[t]{2}{*}{$(n=10)$} & MAP & $74(65-79)$ & $\mathrm{n} / \mathrm{a}$ & $76(68-86)$ & $\mathrm{n} / \mathrm{a}$ & $73(69-83)$ & $\mathrm{n} / \mathrm{a}$ \\
\hline & $\mathrm{SpO}_{2}$ & 97 (97-99) & $\mathrm{n} / \mathrm{a}$ & $99(94-100)$ & $\mathrm{n} / \mathrm{a}$ & $98(96-100)$ & $\mathrm{n} / \mathrm{a}$ \\
\hline Saline & Heart rate & $96(80-103)$ & $-0.5(-16 ; 22)$ & $89(77-103)$ & $-4.5(-19 ; 19)$ & $101(74-110)$ & $7.5(-10 ; 25)$ \\
\hline \multirow[t]{2}{*}{$(n=10)$} & MAP & $7 \mid(59-8 I)$ & $-2.0(-14 ; 12)$ & $75(68-82)$ & $-2(-12 ; 7)$ & $75(67-86)$ & $0.5(-16 ; 22)$ \\
\hline & $\mathrm{SpO}_{2}$ & $100(96-100)$ & $1.0(-1 ; 3)$ & $100(98-100)$ & $0(0 ; 3)$ & $99(97-100)$ & $0(-2 ; 2)$ \\
\hline BupiCloni & Heart rate & $100(74-105)$ & $-1.5(-14 ; 12)$ & $97(76-102)$ & $-0.5(-15 ; 12)$ & $94(73-103)$ & $0(-15 ; 12)$ \\
\hline \multirow[t]{2}{*}{$(n=10)$} & MAP & $79(7 I-86)$ & $3.5(-8 ; 16)$ & $80(70-8 I)$ & $0(-13 ; 9)$ & 76 (63-89) & $1.5(-I I ; \mid 2)$ \\
\hline & $\mathrm{SpO}_{2}$ & $100(98-100)$ & $2(0 ; 3)$ & $100(98-100)$ & I $(0 ; 4)$ & $100(98-100)$ & $0(-3 ; 0)$ \\
\hline BupiEpi & Heart rate & $95(84-123)$ & $4.5(-14 ; 25)$ & $100(85-114)$ & $5(-11 ; 23)$ & $10 \mid(88-|| 2)$ & $8(-6 ; 22)$ \\
\hline \multirow[t]{2}{*}{$(n=10)$} & MAP & $73(67-85)$ & $0(-12 ; 14)$ & $74(67-80)$ & $-3(-14 ; 6)$ & 71 (65-78) & $-2(-14 ; 9)$ \\
\hline & $\mathrm{SpO}_{2}$ & $100(98-100)$ & $2(0 ; 3)$ & $100(99-100)$ & I $(0 ; 3)$ & $100(99-100)$ & $0(0 ; 3)$ \\
\hline
\end{tabular}

Notes: Heart rate is expressed in bpm; MAP in $\mathrm{mmHg}$ and $\mathrm{SpO}_{2}$ in \%. All data are given as median (25th-75th percentile), and compares each group with bupivacaine at the same time point, with differences shown as $\mathrm{HL}$ estimator, with $95 \% \mathrm{Cl}$.

Abbreviations: Bupi, bupivacaine; BupiCloni, bupivacaine with clonidine; BupiEpi, bupivacaine with epinephrine; $\mathrm{Cl}$, confidence interval; $\mathrm{HL}$, Hodges-Lehmann; MAP, mean arterial pressure; n/a, not applicable; Saline, saline control group; $\mathrm{SpO}_{2}$, pulse oximetry; T0, time point 0 min; T30, time point 30 min; T60, time point 60 min.

\section{Microcirculation (= flow measurements)}

Analysis of flow parameters is shown in Table 2. Using the Mann-Whitney test, the bupivacaine group (standard group) showed a significant decrease of flow, compared with the saline group (control group) at T30 and T60 (both $p<0.0001$ ), but was not significantly different from bupivacaine with added clonidine (T30, $p=1.0 ; \mathrm{T} 60, p=0.19$ ), or with added epinephrine (T30, $p=0.48 ; \mathrm{T} 60, p=0.39)$. HL estimators with $95 \%$ CI are shown in Table 2.

\section{Tissue oximetry}

Descriptive data for $\mathrm{SO}_{2}$ measurements at time points T0-T60 are presented in Table 3. Mann-Whitney tests were performed for T0, T30, and T60. No significant differences between the groups were found when comparing bupivacaine with saline at $\mathrm{T} 0(p=0.472)$ and $\mathrm{T} 30(p=0.623)$, whereas differences between both groups at $\mathrm{T} 60$ showed a significant difference $(p=0.0005)$. Comparison of the $\mathrm{SO}_{2}$ values of the bupivacaine group with those of the BupiEpi group showed no significant differences at $\mathrm{T} 0(p=0.382)$, T30 ( $p=0.544)$, or T60 $(p=0.130)$. Moreover, comparison of the $\mathrm{SO}_{2}$ results of the bupivacaine group with those of the BupiCloni group revealed no significant differences at T0, T30, or T60 ( $p=0.519, p=0.520, p=0.211$, respectively). The results for comparisons using HL estimators and lower and upper 95\% CIs are presented in Table 3.

\section{Hemoglobin content}

Measurements of $\mathrm{rHb}$ as a parameter of venous congestion are shown in Table 4. No significant differences of $\mathrm{rHb}$ were found when comparing bupivacaine with the saline control at the time points T0 $(p=0.212)$, T30 $(p=0.226)$, or T60 ( $p=0.104)$. No significant differences were found when comparing the bupivacaine (standard group) with the BupiCloni group (T0, $p=0.472$; T30, $p=0.241$; T60, $p=0.173$ ) or BupiEpi group (T0, $p=0.596$; T30, $p=0.762$; $\mathrm{T} 60, p=0.130)$.

\section{Post hoc analysis (saline versus active comparator)}

Descriptive post hoc testing was performed comparing $\mathrm{SO}_{2}$ as well as nerve blood flow at the given time points between groups. Kruskal-Wallis testing revealed significant differences for nerve blood flow only for T30 $(p<0.0001)$ and T60 ( $p<0.001)$ but not for T0 $(p=1.00)$. Regarding $\mathrm{SO}_{2}$ data, post hoc Kruskal-Wallis testing showed no significant differences between groups for $\mathrm{T} 0$ and $\mathrm{T} 30$ but a significant difference for T60 ( $p=0.047)$.

Thus, pairwise comparisons of saline versus each group (bupivacaine, BupiEpi, or BupiCloni) were performed when applicable. Statistical test results are shown in Table 5.

\section{Discussion}

Our results showed that the application of local anesthetics alone, such as bupivacaine, resulted in relevant nerve blood flow reductions at $\mathrm{T} 30$ and $\mathrm{T} 60$, as shown in previous studies. ${ }^{4,5,8,9,22}$ However, no significant difference for tissue oximetry between bupivacaine versus saline or versus bupivacaine in combination with clonidine or epinephrine was observed. Moreover, the addition of epinephrine or clonidine did not result in any significant alterations of nerve blood flow or tissue oximetry $\left(\mathrm{SO}_{2}\right)$, compared with the bupivacaine standard group. 

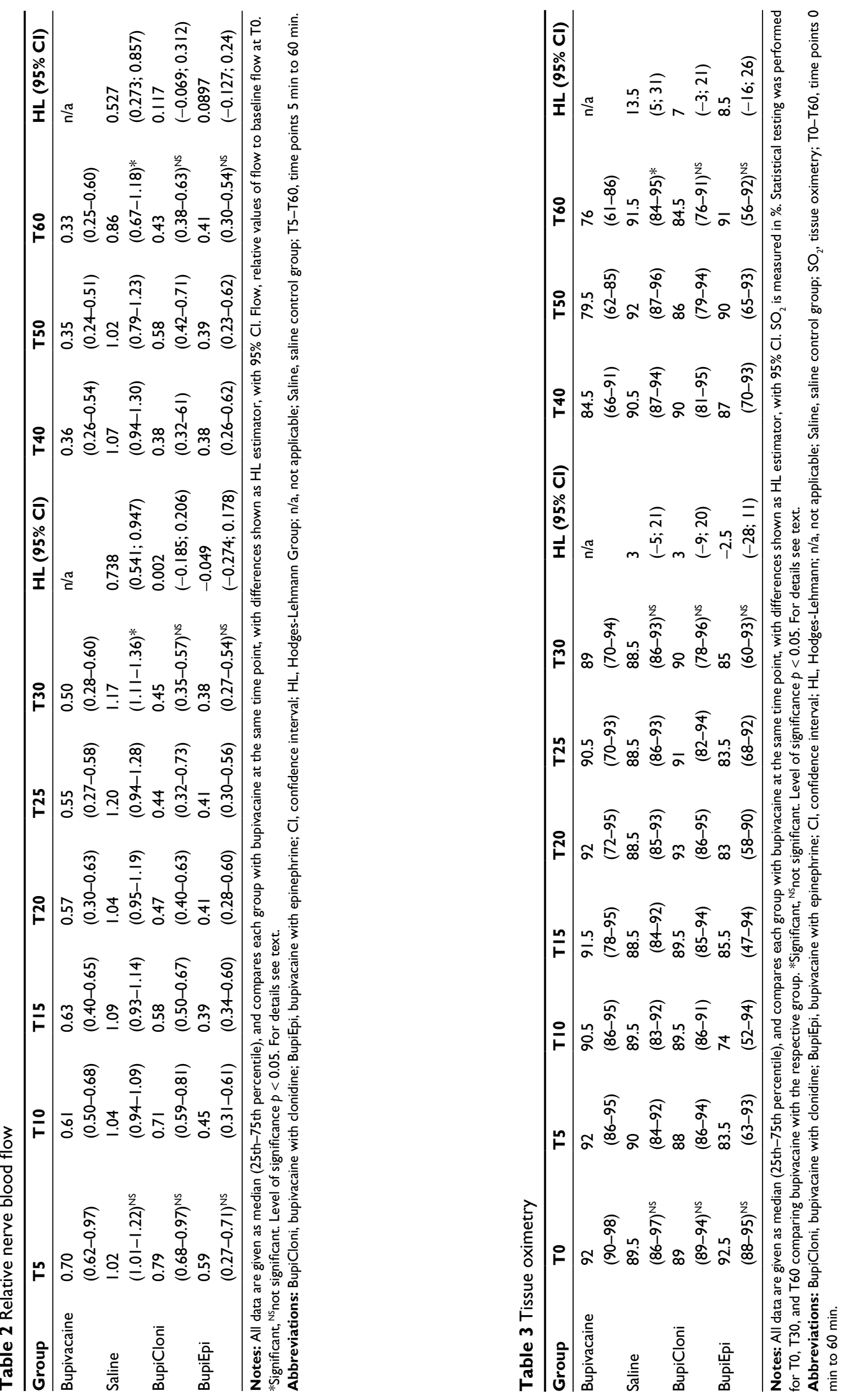


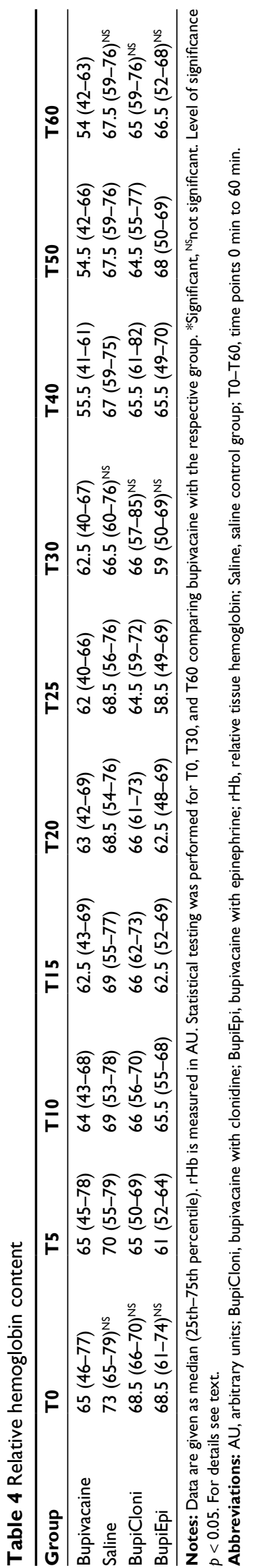

Table 5 Post hoc comparisons

\begin{tabular}{lllll}
\hline Group & Parameter & T0 & T30 & T60 \\
\hline Saline vs Bupi & Rel. NBF & $\mathrm{n} / \mathrm{a}$ & $<0.00 \mathrm{I}$ & $<0.00 \mathrm{I}$ \\
& $\mathrm{SO}_{2}$ & $\mathrm{n} / \mathrm{a}$ & $\mathrm{n} / \mathrm{a}$ & 0.003 \\
Saline vs BupiCloni & $\mathrm{Rel} \mathrm{NBF}$ & $\mathrm{n} / \mathrm{a}$ & $<0.00 \mathrm{I}$ & 0.004 \\
& $\mathrm{SO}_{2}$ & $\mathrm{n} / \mathrm{a}$ & $\mathrm{n} / \mathrm{a}$ & 0.63 \\
Saline vs BupiEpi & $\mathrm{Rel} \mathrm{NBF}$ & $\mathrm{n} / \mathrm{a}$ & $<0.00 \mathrm{I}$ & $0.00 \mathrm{I}$ \\
& $\mathrm{SO}_{2}$ & $\mathrm{n} / \mathrm{a}$ & $\mathrm{n} / \mathrm{a}$ & $0.48 \mathrm{I}$ \\
\hline
\end{tabular}

Notes: Data are given as uncorrected $p$-value data of pairwise comparisons using Mann-Whitney testing; $n / a$ due to not significant Kruskal-Wallis testing.

Abbreviations: Bupi, bupivacaine; BupiCloni, bupivacaine with clonidine; BupiEpi, bupivacaine with epinephrine; n/a, not applicable; Rel. NBF, relative nerve blood flow; Saline, saline control group; $\mathrm{SO}_{2}$, tissue oximetry; T0, time point 0 min; T30, time point $30 \mathrm{~min}$; T60, time point $60 \mathrm{~min}$.

Epinephrine enhances nerve block duration, mostly due to reduction of local tissue clearance and prolonged concentration of the local anesthetic in the nerve and perineural tissue. ${ }^{7}$ It is regularly used as an adjunct for local anesthetics to reduce systemic absorption and consecutive toxic phenomena of the injected local anesthetic. Furthermore, many clinicians assume a shortened nerve block onset time and prolonged anesthetic nerve blockade when epinephrine is used. ${ }^{20}$

However, some authors believe that when used as an adjunct, epinephrine might be an independent risk factor for nerve damage due to relevant ischemia. ${ }^{5,8,23}$ Our study showed no further statistically significant impairment of nerve blood flow (when compared with bupivacaine alone). However, two nerves of the BupiEpi group did have relevant desaturations during measurements $\left(\mathrm{SO}_{2}\right.$ nadir values of $3 \%$ at T20 and $10 \%$ at T10 in another nerve). Thus, despite no significant difference between both groups of bupivacaine, with and without epinephrine, we would recommend not to use epinephrine in a patient population with preexisting peripheral nerve damage (i.e., diabetic polyneuropathy).

Clonidine is widely used as an adjunct to local anesthetic in different peripheral nerve blockades. ${ }^{20,24}$ It prolongs the duration of the blockade due to unknown mechanisms. Due to its alpha-2-adrenergic effects, vasodilatation might be assumed in peripheral tissues, without risk of nerve ischemia. However, clinical side effects, such as sedation or bradycardia, are regularly observed..$^{20,25}$ In experimental models of peripheral neuropathy, clonidine acts as an anti-inflammatory drug. ${ }^{26-28}$ Thus, its clinical effects and anti-inflammatory potential are interesting factors for the regional anesthetist. Our experimental data give further evidence of safety when perineural clonidine is used in combination with local anesthetics. No further alterations of nerve microcirculation or tissue oximetry were observed, compared with bupivacaine alone.

Systemic data did not differ, in any way that was clinically relevant, between the time points $\mathrm{T} 0, \mathrm{~T} 30$, and $\mathrm{T} 60$ when 
compared between each group. This is important due to the response of nerve $\mathrm{SO}_{2}$ to central hypoxia and cardiovascular changes as described by Ibrahim et al..$^{29}$ Moreover, this aspect is a potential bias within previous published studies of nerve blood flow measurements in animals where changes in oxygen saturation and circulation were not, or were inadequately, controlled.

Laser-Doppler flowmetry is an established method for investigating nerve blood flow alterations. ${ }^{4,9,30}$ Nevertheless, responses of the underlying tissues to blood flow reductions have been poorly investigated for local anesthetic applications. The use of the $\mathrm{O} 2 \mathrm{C}$ device enabled us to investigate the consequences of (microvascular) nerve blood flow alterations with regard to local post-capillary oximetry and hemoglobin content as critical parameters for tissue hypoxia and potential tissue damage.

\section{Limitations}

Our experimental study has several limitations, which should be kept in mind before transferring to clinical practice. First, the differences between the results in this animal study might not be easily extrapolated to humans, due to possible differences in nerve blood flow and underlying regulative mechanisms between pigs and humans. Changes in vascular tone might be influenced by general anesthesia, the surgical preparation, ${ }^{31}$ and the mounted probe resting on the nerves. Changes in blood pressure, systemic oxygen saturation, and end tidal carbon dioxide might have an impact on nerve blood flow due to limited autoregulation of nerve blood flow. ${ }^{30,32}$ These important bias factors are controlled for in our study by invasive blood pressure monitoring, as well as the use of controlled mechanical ventilation with fixed inspired oxygen fraction, and the use of capnometry for establishing normocapnia. Furthermore, our investigation focused only on median nerves, but potential differences between nerve vasculature must be regarded. However, Kihara et al showed no significant differences between different nerve types or fascicle size. ${ }^{32}$ Our measurements were performed for $60 \mathrm{~min}$, which is higher than in previous studies. Nevertheless, the vasoconstrictive effects of the test solutions persisted for longer time periods. Further studies should evaluate this aspect using long-term measurements and include histological or electrophysiological evaluation. Measurement of compound muscle action potential might be a helpful approach in further studies for assessing the acute and long-term effects of the investigated interventions as shown in previous studies. ${ }^{33,34}$ "Downstream" (distal) measurements of overall tissue or nerve tissue perfusion and oxygenation by using near-infrared spectroscopy or other methods as a result of block-related vasodilation might be another interesting topic. ${ }^{35}$
Neurotoxicity of local anesthetics is not caused solely by ischemia as a result of reduced tissue perfusion. Bupivacaine was shown to be a weak uncoupler of mitochondrial oxidative phosphorylation resulting in apoptosis in neural cells. ${ }^{36,37}$

\section{Conclusion}

Based on our experimental study results, the addition of epinephrine or clonidine to bupivacaine does not result in any relevant changes of nerve blood flow, or tissue oximetry, compared with bupivacaine alone. However, bupivacaine does show a relevant depression of nerve blood flow without resulting in severe nerve tissue ischemia. Thus, impairment of nerve blood flow by bupivacaine alone is not modified in a relevant way by the combination of bupivacaine with clonidine. The combination of bupivacaine with epinephrine shows no statistically significant differences in nerve tissue perfusion or tissue oxygen saturation. Ischemia as a consequence of the use of bupivacaine alone or in combination with epinephrine or clonidine was a rare event in our experimental study. Thus, ischemia is not a potential clinical relevant risk factor of peripheral nerve damage resulting from the administration of the aforementioned drugs.

\section{Acknowledgment}

This study was performed by using departmental funding.

\section{Disclosure}

TW received consultancy fees from $B$. Braun. HW received speaker fees from Syntetica, B. Braun, Teleflex, and Vygon. TS received speaker fees from B. Braun, Teleflex, and Vygon. The other authors report no conflicts of interest in this work.

\section{References}

1. Bell MA, Weddell AG. A descriptive study of the blood vessels of the sciatic nerve in the rat, man and other mammals. Brain. 1984;107 (Pt 3): 871-898.

2. Bell MA, Weddell AG. A morphometric study of intrafascicular vessels of mammalian sciatic nerve. Muscle Nerve. 1984;7(7):524-534.

3. Mizisin AP, Weerasuriya A. Homeostatic regulation of the endoneurial microenvironment during development, aging and in response to trauma, disease and toxic insult. Acta Neuropathol. 2010;121(3):291-312.

4. Myers RR, Heckman HM. Effects of local anesthesia on nerve blood flow: studies using lidocaine with and without epinephrine. Anesthesiology. 1989;71(5):757-762.

5. Hogan QH. Pathophysiology of peripheral nerve injury during regional anesthesia. Reg Anesth Pain Med. 2008;33(5):435-441.

6. Neal JM, Barrington MJ, Brull R, et al. The second ASRA practice advisory on neurologic complications associated with regional anesthesia and pain medicine: executive summary 2015. Reg Anesth Pain Med. 2015;40(5):401-430.

7. Neal JM. Effects of epinephrine in local anesthetics on the central and peripheral nervous systems: neurotoxicity and neural blood flow. Reg Anesth Pain Med. 2003;28(2):124-134. 
8. Partridge BL. The effects of local anesthetics and epinephrine on rat sciatic nerve blood flow. Anesthesiology. 1991;75(2):243-250.

9. Bouaziz H, Iohom G, Estèbe JP, Campana WM, Myers RR. Effects of levobupivacaine and ropivacaine on rat sciatic nerve blood flow. $\mathrm{Br} J$ Anaesth. 2005;95(5):696-700.

10. Kilkenny C, Browne WJ, Cuthill IC, Emerson M, Altman DG. Improving bioscience research reporting: the ARRIVE guidelines for reporting animal research. PLoS Biol. 2010;8(6):e1000412.

11. Steinfeldt T, Graf J, Schneider J, et al. Histological consequences of needle-nerve contact following nerve stimulation in a pig model. Anesthesiol Res Pract. 2011;2011:591851.

12. Steinfeldt $T$, Wiesmann $T$, Nimphius $W$, et al. Perineural hematoma may result in nerve inflammation and myelin damage. Reg Anesth Pain Med. 2014;39(6):513-519.

13. Wiesmann $\mathrm{T}$, Bornträger $\mathrm{A}$, Vassiliou $\mathrm{T}$, et al. Minimal current intensity to elicit an evoked motor response cannot discern between needle-nerve contact and intraneural needle insertion. Anesth Analg. 2013;118(3):681-686.

14. Forst T, Hohberg C, Tarakci E, Forst S, Kann P, Pfützner A. Reliability of lightguide spectrophotometry (O2C $($ ) for the investigation of skin tissue microvascular blood flow and tissue oxygen supply in diabetic and nondiabetic subjects. J Diabetes Sci Technol. 2008;2(6):1151-1156.

15. Beckert S, Witte MB, Königsrainer A, Coerper S. The impact of the micro-lightguide $\mathrm{O} 2 \mathrm{C}$ for the quantification of tissue ischemia in diabetic foot ulcers. Diabetes Care. 2004;27(12):2863-2867.

16. Scheeren TW. Monitoring the microcirculation in the critically ill patient: reflectance spectroscopy. Intensive Care Med. 2011;37(6):1045-1046.

17. Schmelzer JD, Zochodne DW, Low PA. Ischemic and reperfusion injury of rat peripheral nerve. Proc Natl Acad Sci U SA. 1989;86(5):1639-1642.

18. Kihara M, Zollman PJ, Schmelzer JD, Low PA. The influence of dose of microspheres on nerve blood flow, electrophysiology, and fiber degeneration of rat peripheral nerve. Muscle Nerve. 1993;16(12):1383-1389.

19. Nukada H, Powell HC, Myers RR. Spatial distribution of nerve injury after occlusion of individual major vessels in rat sciatic nerves. $J \mathrm{Neu}$ ropathol Exp Neurol. 1993;52(5):452-459.

20. Kirksey MA, Haskins SC, Cheng J, Liu SS. Local anesthetic peripheral nerve block adjuvants for prolongation of analgesia: a systematic qualitative review. PLoS One. 2015;10(9):e0137312.

21. Krug A. Microcirculation and oxygen supply: method of so-called O2C. Phlebologie. 2007;36:300-312.

22. Palmer GM, Cairns BE, Berkes SL, Dunning PS, Taylor GA, Berde CB. The effects of lidocaine and adrenergic agonists on rat sciatic nerve and skeletal muscle blood flow in vivo. Anesth Analg. 2002;95(4):1080-1086.

23. Selander D, Brattsand R, Lundborg G, Nordborg C, Olsson Y. Local anesthetics: importance of mode of application, concentration and adrenaline for the appearance of nerve lesions. An experimental study of axonal degeneration and barrier damage after intrafascicular injection or topical application of bupivacaine (Marcain). Acta Anaesthesiol Scand. 1979;23(2):127-136.
24. Axelsson K, Gupta A. Local anaesthetic adjuvants: neuraxial versus peripheral nerve block. Curr Opin Anaesthesiol. 2009;22(5): 649-654.

25. Pöpping DM, Elia N, Marret E, Wenk M, Tramèr MR. Clonidine as an adjuvant to local anesthetics for peripheral nerve and plexus blocks: a meta-analysis of randomized trials. Anesthesiology. 2009;111(2):406-415

26. Lavand'homme PM, Eisenach JC. Perioperative administration of the $\alpha 2$-adrenoceptor agonist clonidine at the site of nerve injury reduces the development of mechanical hypersensitivity and modulates local cytokine expression. Pain. 2003;105(1-2):247-254.

27. Romero-Sandoval A, Eisenach JC. Perineural clonidine reduces mechanical hypersensitivity and cytokine production in established nerve injury. Anesthesiology. 2006;104(2):351-355.

28. Romero-Sandoval A, Eisenach JC. Clonidine reduces hypersensitivity and alters the balance of pro- and anti-inflammatory leukocytes after local injection at the site of inflammatory neuritis. Brain Behav Immun. 2007;21(5):569-580.

29. Ibrahim S, Laude EA, Bee D, Eaton S, Ward JD, Harris ND. Combined microlightguide spectrophotometry and microendoscopy for measurement of oxygen saturation in peripheral nerves. Physiol Meas. 1999;20(1):65-73

30. Rundquist I, Smith QR, Michel ME, Ask P, Oberg PA, Rapoport SI. Sciatic nerve blood flow measured by laser Doppler flowmetry and [14C]iodoantipyrine. Am J Physiol. 1985;248(3 Pt 2):H311-H317.

31. Sugimoto H, Monafo WW, Eliasson SG. Regional sciatic nerve and muscle blood flow in conscious and anesthetized rats. Am J Physiol. 1986;251(6 Pt 2):H1211-H1216.

32. Kihara M, Weerasuriya A, Low PA. Endoneurial blood flow in rat sciatic nerve during development. J Physiol. 1991;439:351-360.

33. Kirchmair L, Ströhle M, Löscher WN, Kreutziger J, Voelckel WG, Lirk P. Neurophysiological effects of needle trauma and intraneural injection in a porcine model: a pilot study. Acta Anaesthesiol Scand. 2016;60(3):393-399.

34. Atanassoff PG, Weiss BM, Brull SJ, et al. Compound motor action potential recording distinguishes differential onset of motor block of the obturator nerve in response to etidocaine or bupivacaine. Anesth Analg. 1996;82(2):317-320.

35. Tighe PJ, Elliott CE, Lucas SD, Boezaart AP. Noninvasive tissue oxygen saturation determined by near-infrared spectroscopy following peripheral nerve block. Acta Anaesthesiol Scand. 2011;55(10): 1239-1246.

36. Myers RR, Kalichman MW, Reisner LS, Powell HC. Neurotoxicity of local anesthetics: altered perineurial permeability, edema, and nerve fiber injury. Anesthesiology. 1986;64(1):29-35.

37. Kalichman MW, Powell HC, Myers RR. Quantitative histologic analysis of local anesthetic-induced injury to rat sciatic nerve. J Pharmacol Exp Ther. 1989;250(1):406-413.

\section{Journal of Pain Research}

\section{Publish your work in this journal}

The Journal of Pain Research is an international, peer reviewed, open access, online journal that welcomes laboratory and clinical findings in the fields of pain research and the prevention and management of pain. Original research, reviews, symposium reports, hypothesis formation and commentaries are all considered for publication.
The manuscript management system is completely online and includes a very quick and fair peer-review system, which is all easy to use. Visit http://www.dovepress.com/testimonials.php to read real quotes from published authors. 